\title{
UTILIZAÇÃO DA ESPECTROMETRIA DE MASSA MALDI-TOF PARA AVALIAÇÃO MICROBIOLÓGICA DE LEITE E DERIVADOS
}

\section{Utilization of MALDI-TOF Mass Spectrometry for microbiological evaluation of milk and dairy products}

\author{
Gustavo Lucas Costa Valente ${ }^{*}$, Marcelo Resende de Souza ${ }^{l}$
}

\begin{abstract}
RESUMO
Leite e seus derivados são alimentos que se destacam pelo elevado teor nutritivo. Essa característica permite que seja encontrada uma grande diversidade de microorganismos nesses produtos, incluindo aqueles considerados desejáveis e indesejáveis. Associado a isso, um elevado volume de leite tem sido produzido mundialmente, demandando que métodos mais práticos e acurados, como a espectrometria de massa MALDI-TOF, sejam aplicados para avaliação microbiológica de produtos lácteos. Essa metodologia se baseia na ionização e dessorção de proteínas microbianas, que em seguida são aceleradas em um tubo a vácuo. De acordo com o tempo de voo ao longo do tubo das diferentes partículas ionizadas que compunham a amostra, são formados espectros característicos que podem ser comparados aos espectros presentes no banco de dados do aparelho, permitindo uma identificação do micro-organismo. Muitos estudos científicos têm demonstrado que a identificação por MALDI-TOF de distintos microorganismos isolados de produtos lácteos (leite fluido, queijos e leites fermentados) foi compatível com o resultado obtido por métodos de sequenciamento genético (gene rRNA 16S), que é considerado o padrão-ouro para identificação microbiana. Apesar de ser um método novo e que demanda um considerável investimento para aquisição do aparelho, seu desempenho tem sido satisfatório e promissor. Portanto, há uma grande perspectiva futura para sua utilização de forma mais efetiva na identificação de micro-organismos provenientes de produtos lácteos.
\end{abstract}

Palavras-chave: microbiologia de leite; análise proteômica; identificação microbiana.

1 Universidade Federal de Minas Gerais, Escola de Veterinária, Av. Presidente Antônio Carlos, 6.627, 31.270-901, Belo Horizonte, MG, Brasil. E-mail: gustlcv.vet@gmail.com

* Autor para correspondência

Recebido / Received: 17/05/2019

Aprovado / Approved: 23/10/2019 


\begin{abstract}
Milk and its derivatives are foods that are distinguished by their high nutritional value. This characteristic allows a wide variety of microorganisms to be found in such products, including those considered desirable and undesirable. In addition, a large volume of milk has been produced worldwide, demanding more practical and accurate methods, such as MALDI-TOF mass spectrometry, to be applied for the microbiological evaluation of dairy products. This methodology is based on the ionization and desorption of microbial proteins, which are then accelerated in a vacuum tube. According to the time-of-flight along the tube of the different ionized particles composing the sample, characteristic spectra are formed and compared to the spectra present in the database, allowing the identification of the microorganism. Many scientific studies have demonstrated that the identification by MALDI-TOF of distinct microorganisms isolated from dairy products (milk, cheeses and fermented milks) was compatible with the result obtained by genetic sequencing methods (16S rRNA gene), which is considered the gold standard method for microbial identification. Although this is a new method and requires considerable investment to acquire the device, its performance has been satisfactory and promising. Therefore, there is a great future perspective that its use will be more effective for the identification of dairy microorganisms.
\end{abstract}

Keywords: milk microbiology; proteomic analysis; microbial identification.

\section{INTRODUÇÃO}

O leite é um alimento essencial à nutrição humana, sendo produzido em todo o mundo. Essa importância pode ser comprovada pelo aumento de mais de $50 \%$ da produção mundial dessa commodity nas últimas três décadas, atingido o valor de 831 milhões de toneladas em 2017. A atividade leiteira também é uma prática econômica presente em aproximadamente 150 milhões de lares em todo o mundo, exercida principalmente por pequenos agricultores de países em desenvolvimento (FAO, 2019).

Da mesma forma, a produção de leite tem se apresentado como uma das principais atividades agropecuária e econômica no contexto brasileiro. Segundo dados do Instituto Brasileiro de Geografia e Estatística (IBGE), após dois anos de queda do volume de leite produzido no Brasil em virtude da recessão, em 2017 foram captados 24,12 bilhões de litros, sendo esse montante $4,1 \%$ maior que o apresentado em 2016. Em 2018 esse valor apresentou uma pequena elevação atingindo a marca de aproximadamente 24,44 bilhões de litros de leite captados (IBGE, 2019).

A projeção da produção de leite no Brasil em 2019 é de crescimento de $2 \%$ do volume total (USDA, 2019). Embora possa ser considerado modesto, o aumento da produção nacional tende a apresentar uma continuidade dos dois últimos anos, mesmo considerando a situação econômica atual do país.

De forma a acompanhar o progresso que a cadeia de produção leiteira vem apresentando, é fundamental que haja um aprimoramento e desenvolvimento das técnicas de avaliação da qualidade do leite, principalmente do ponto de vista microbiológico. Nesse contexto, métodos como a espectrometria de massa MALDI-TOF têm se mostrado promissores para atender a essa necessidade, tanto devido sua praticidade, como também pela eficácia de análise (SINGHAL et al., 2015). 
Baseado nisso, o objetivo desse trabalho foi elaborar uma revisão de literatura científica sobre o uso da espectrometria de massa MALDI-TOF para a avaliação da qualidade microbiológica de leite e seus derivados.

\section{REFERENCIAL TEÓRICO}

\section{Coleta de dados}

A pesquisa por artigos científicos relacionados ao tema da revisão foi realizada em plataformas digitais de buscas direcionados à área acadêmica, como "Google Scholar", "PubMed" e "Portal CAPES". Os descritores contemplados nas buscas foram termos relacionados à metodologia abordada (como "mass spectrometry" e "MALDI-TOF") associada a produtos lácteos ("dairy products", "milk" "fermented milk" e "cheese").

\section{Microbiologia de leite e produtos lácteos}

Leite e seus derivados são alimentos muito importantes do ponto de vista nutricional devido sua composição química. Suas propriedades nutritivas se devem aos teores e perfis de lipídios, proteínas, carboidratos, minerais e vitaminas, que desempenham importante função na alimentação humana (MARANGONI et al., 2019). Entretanto, devido a essa propriedade, este também se constitui como excelente substrato para o desenvolvimento de micro-organismos. Segundo Quigley et al. (2013), o alto teor de nutrientes presente nesse produto é o fator fundamental para que o leite apresente uma variedade de micro-organismos. Por causa disso, a microbiota presente em produtos lácteos é bastante diversificada, podendo ser formada por micro-organismos indesejáveis e desejáveis (BOOR et al., 2017).

Entre os micro-organismos considerados benéficos, as bactérias ácido-lácticas (BAL), representadas principalmente por
Lactobacillus spp. e Lactococcus spp., têm grande destaque. Devido ao metabolismo fermentativo, BAL são amplamente utilizadas para elaboração de produtos lácteos fermentados, bem como participam dos processos de maturação de queijos (HAMET et al., 2015). Além da importância tecnológica, algumas amostras de BAL podem ainda ser consideradas probióticos, ou seja, conferem benefícios à saúde do hospedeiro quando administradas em concentrações adequadas (FAO/WHO, 2002). Além de bactérias, em alguns queijos e no kefir podem ser encontrados bolores e leveduras capazes de conferir sabor característico, além de serem potencialmente benéficos ao consumidor (GAROFALO et al., 2015).

Por outro lado, alguns derivados lácteos são muito passíveis de deterioração microbiana, devido sua composição nutritiva e elevado teor de umidade. Micro-organismos fermentadores e psicrotróficos, além de outros tipos de bolores e leveduras, são capazes de alterar as características normais do produto, tornando-o impróprio para o consumo (QUIGLEY et al., 2013). Além disso, esses produtos podem ser veículos de patógenos envolvidos em quadros de doenças transmitidas por alimentos (DTA), como Listeria monocytogenes, Escherichia coli, Staphylococcus aureus, Salmonella enterica, Campylobacter jejuni, Coxiella burnetii, Brucella abortus e Mycobacterium bovis (VERRAES et al., 2015).

Dada à complexidade de organismos que podem estar presentes na microbiota de derivados lácteos, associado às previsões de aumento no volume de produção desses alimentos, torna-se importante utilizar métodos rápidos, práticos e acurados para a inspeção sanitária e controle de qualidade de tais produtos. Nesse contexto, a espectrometria de massa MALDI-TOF é uma metodologia que tem se mostrado muito promissora no atendimento desses quesitos. 


\section{Espectrometria de massa MALDI-TOF}

\section{Histórico}

A espectrometria de massa é uma técnica analítica precisa desenvolvida no início do século $\mathrm{XX}$, que se baseia na identificação e quantificação de compostos a partir da determinação da relação massa/carga $(\mathrm{m} / \mathrm{z}) \mathrm{de}$ estruturas químicas ionizadas em fase gasosa (INCZEDY et al., 1998). Na década de 1970, pesquisadores começaram a tentar aplicar tal princípio para identificar micro-organismos. Anhalt e Fenselau (1975) combinaram a técnica de espectrometria de massa com a aplicação de pirólise sobre espécimes bacterianos Gram-positivo. Tal associação resultou na formação de espectros a partir de moléculas de baixo peso submetidas à pirólise, como fosfolipídeos e ubiquinonas, oriundas da membrana plasmática. Nessa época, muitos pesquisadores encontravam dificuldades em utilizar a espectrometria de massa para essa finalidade, pois o laser irradiado sobre as amostras levava a quebra das moléculas de proteínas, comprometendo sua integridade original. Posteriormente, esse problema foi minimizado a partir do momento em que as proteínas começaram a ser introduzidas em matrizes capazes de protegê-las desses danos (TANAKA et al., 1988).

Com o desenvolvimento da ionização por dessorção a laser assistido por matriz, (matrix assisted laser desorption ionization - MALDI), a metodologia que era utilizada basicamente em estudos químicos, passou a ser mais amplamente empregada na análise de grandes moléculas biológicas. Proteínas puderam ser ionizadas pela adição ou perda de prótons, sem comprometer sua estrutura básica, possibilitando sua caracterização (SINGHAL et al., 2015).

A partir dos anos 1990, a técnica passou a ser utilizada de forma mais ampla para tal objetivo, resultando no aumento do número de estudos publicados. A maior praticidade observada se relacionou ao fato de que, os espectros formados pela análise de microorganismos por MALDI-TOF, passaram a ser obtidos de forma mais simples e rápida, devido à dispensabilidade de se realizar prétratamentos das células presentes na amostra. Bactérias passaram a ser amostradas da própria colônia, sendo diretamente misturadas à matriz e introduzidas no espectrômetro (HOLLAND et al., 1996).

Nos anos seguintes, com o crescimento da utilização do método para identificação microbiológica, foram construídos e validados banco de dados de perfis espectrais, que servem como fonte de comparação entre os espectros formados pelas análises de amostras desconhecidas (KEYS et al., 2004).

\section{Princípio e metodologia}

De uma forma geral, um espectrômetro de massa é composto por uma fonte de ionização, um analisador de massas, um detector de íons e um sistema de banco de dados (CANTÚ et al., 2008). Inicialmente, a amostra a ser analisada necessita ser tratada com uma matriz constituída por uma solução de compostos orgânicos com alta capacidade de absorção de energia. A solução da matriz é constituída de água, um ácido forte e uma mistura de solventes orgânicos contendo etanol, metanol ou acetonitrila, que são capazes de penetrar a parede celular dos micro-organismos e extrair as proteínas intracelulares. Após a secagem da matriz, essa se cristaliza, o que resulta na co-cristalização da amostra nela retida. Na sequência, um raio laser é emitido sobre a amostra, e a absorção dessa energia pela matriz desencadeia os processos de dessorção e ionização do analito (HORNEFFER et al., 2001).

Os íons protonados, em seguida, são acelerados em um tubo a vácuo, onde serão separados em função da proporção $\mathrm{m} / \mathrm{z}$. A partir dessa segregação, os analitos carregados podem ser detectados e mensurados, baseando em seus tempos de voo (time-of-flight TOF) ao longo do tubo, já que o tempo de 
deslocação até o detector é proporcional à massa dos íons. (SINGHAL et al., 2015).

O princípio TOF se baseia no fato de que, quando elementos ionizados possuem a mesma carga, suas velocidades serão inversamente proporcionais à raiz quadrada de suas massas. Desse modo, os tempos de voos dos diferentes analitos serão determinados pelas suas massas, sendo que, quanto menor a relação $\mathrm{m} / \mathrm{z}$, mais rápido o íon atingirá $\mathrm{o}$ detector (PAIVA et al., 2010). De acordo com o tempo de voo obtido pelos diferentes elementos ionizados, é formado um espectro característico de cada amostra, denominado de impressão digital de massa de peptídeos (peptide mass fingerprint - PMF). Para formação dos PMF's são consideradas partículas com massa entre 2 a $20 \mathrm{kDa}$. Essa faixa contempla as proteínas ribossomais que são características de cada organismo, representado $60-70 \%$ da matéria seca de uma célula microbiana (WATTAL et al., 2017). Segundo Angeletti (2017), cerca de 50 proteínas com massas contidas nesse intervalo podem ser identificadas nos ribossomos de micro-organismos.

A identificação de micro-organismos é feita comparando o PMF obtido na análise com os PMF's contidos no banco de dados. Atualmente, existem quatro bancos de dados comerciais de MALDI-TOF: MALDI Biotyper (Bruker Daltonics, Bremen, Alemanha), Saramis (AnagnosTec, Potsdam, Alemanha) Andromas (Andromas, Paris, França) e VitekMS (bioMérieux, Marcy l'Etoile, França) (POSTERARO et al., 2013). Entretanto, muitos grupos de pesquisa têm desenvolvido softwares e banco de dados de livre compartilhamento entre a comunidade científica (BÖHME et al., 2012a).

\section{Vantagens e desafios}

Comparado a outros métodos de identificação de micro-organismos, como por exemplo os testes convencionais, imunológicos, moleculares, florescentes, de sequenciamento genético e metagenômicos, o MALDI-TOF apresenta algumas vantagens que justificam sua utilização e a realização de estudos. Dentre esses benefícios, podem ser citados a velocidade, a acurácia e o fácil treinamento dos operadores. Embora a aquisição do equipamento necessite de um alto investimento, o custo da análise por MALDI-TOF é mais barato que as moleculares e imunológicas (STEVENSON et al., 2010; SINGHAL et al., 2015).

Essa técnica pode ser considerada a principal ferramenta analítica no campo da proteômica devido a sua elevada sensibilidade, exatidão e precisão (BARREIRO, 2010). MALDI-TOF tem se apresentado como uma técnica que poder ser executada de forma rápida e simples, ao mesmo tempo em que se destaca quanto à alta reprodutibilidade. Além disso, mais de $90 \%$ dos isolados bacterianos são identificados em nível de espécie e $98 \%$ em nível de gênero, enquanto apenas menos de $1 \%$ são identificados incorretamente (MURRAY, 2012).

Segundo Angeletti (2017), o MALDITOF também é capaz de identificar microorganismos em amostras de distintas origens, com um tempo curto entre sua coleta e o resultado final, além de demonstrar uma sensibilidade elevada, sendo capaz de analisar amostra com menos de $10^{4}$ UFC.

Se por um lado o MALDI-TOF se apresenta como uma metodologia inovadora, de fácil execução e resultados precisos, por outro existem alguns fatores relacionados à técnica que podem causar algumas dificuldades na identificação de amostras. O primeiro deles seria a necessidade prévia para cultivo dos micro-organismos. Portanto, para microorganismos de fastidioso desenvolvimento in vitro esta técnica pode não ser a mais indicada. Relatos sobre problemas na identificação de novos micro-organismos geralmente são centrados na ausência de informações no banco de dados no que se diz respeito à diversidade microbiana. Dessa forma, se 
fazem necessários a atualização, criação e refinamento de banco de dados a partir da incorporação de PFM's de outras origens (VELOO et al., 2016; SEUYLEMEZIAN et al., 2018).

Outro problema relatado por alguns autores se deve à dificuldade que a técnica pode apresentar em distinguir espécies que são muito relacionadas. Segundo Paauw et al. (2015), a diferenciação entre Shigella spp. e Escherichia coli pode ser um exemplo desse empecilho, uma vez que ambas se apresentam muito próximas, do ponto de vista filogenético. Da mesma forma, já foram descritos dificuldades na discriminação de bactérias do gênero Streptococcus, de diferentes amostras de Staphylococcus aureus e Enterococcus faecium e na distinção entre Bacillus cereus e B. anthracis (LASCH et al., 2014; MARÍN et al., 2017; PAUKER et al., 2018).

A natureza química dos constituintes da parede celular microbiana é um fator capaz de modificar a acurácia da identificação pelo MALDI-TOF, pois de acordo com a composição dessa estrutura, é necessário que seja realizado um preparo adequado na amostra para uma caracterização mais fidedigna. Bactérias que se coram como Gram negativo geralmente podem ser identificadas diretamente, ao se coletar uma única colônia e transferi-la diretamente para a placa contendo a matriz. Para a análise de microorganismos que se coram como Gram positivo, Staphylococcus spp. e bactérias não fermentadoras de açúcares, é desejável que as amostras sejam previamente tratadas com ácido fórmico para aumentar a capacidade de identificação pelo MALDI-TOF (ALATOOM et al., 2011; SAFFERT et al.,2011).

\section{Aplicação do MALDI-TOF na análise microbiológica de leite e derivados}

Angelakis et al. (2011) investigaram a acurácia e viabilidade da aplicação do
MALDI-TOF para identificação de BAL presentes em leites fermentados. Como padrão comparativo, as amostras também foram caracterizadas por testes moleculares como sequenciamento dos genes tuf e rRNA 16S. Comparando os resultados obtidos pelas diferentes metodologias, pode-se perceber uma semelhança entre $92 \%$ das identificações. A diferença entre identificações foi observada em uma única amostra, na qual o microorganismo encontrado, segundo o MALDITOF, era L. paracasei, enquanto que as técnicas moleculares (sequenciamento dos genes tuf e rRNA 16S) o classificaram como L. casei. Embora os resultados mostrem uma diferença na identificação, alguns estudos demonstraram que, filogeneticamente, ambos os lactobacilos apresentam uma considerável semelhança (BOTTARI et al., 2017). Conforme já abordado, a análise por MALDI-TOF de amostras muito próximas geneticamente pode levar a alguns vieses na identificação, principalmente quando isso se associa a ausências de informações mais refinadas no banco de dados (PAAUW et al., 2015).

Dušková et al. (2012) identificaram amostras de Lactobacillus spp. provenientes de leite de ovelha, queijos, lácteos fermentados, manjar branco (sobremesa feita à base de leite e creme) e produtos cárneos, pelos métodos de PCR e MALDI-TOF. Como padrão comparativo, as amostras também foram submetidas à identificação pelo sequenciamento do gene rRNA $16 \mathrm{~S}$. Os resultados encontrados pelos autores podem ser observados na Tabela 1.

Apesar das altas congruências entre a PCR e o MALDI-TOF, foram observadas taxas de sucesso na identificação de espécies de $77 \%$ para PCR e $93 \%$ para o MALDI-TOF, utilizando a técnica de sequenciamento do gene rRNA $16 \mathrm{~S}$ como padrão comparativo. Com isso, os pesquisadores concluíram que o MALDI-TOF pode ser utilizado como um método simples e rápido para identificação de 
Lactobacillus. Entretanto, problemas com a discriminação entre espécies de lactobacilos muito próximas geneticamente também foi um ponto levantado pelos autores, que ainda destacaram a necessidade de combinar o MALDI-TOF com outras técnicas de genotipagem para uma identificação mais confiável.

No estudo de Nacef et al. (2017) foram realizadas as identificações, por MALDITOF, de BAL mesofílicas isoladas de queijo Maroilles, produzido na França. Foram realizados os cultivos, em ágar $\mathrm{MRS}$, da casca e do meio dos queijos produzidos com leite cru e pasteurizado, obtendo 105 colônias nos queijos elaborados com leite cru (38 na casca e 67 no meio) e 92 nos queijos com leite pasteurizado (39 na casca e 53 no meio). Dentre essas amostras, o MALDI-TOF identificou três gêneros pertencentes ao grupo das BAL: Lactobacillus, Enterococcus e Leuconostoc. Lactobacillus spp. foram os micro-organismos mais presentes, representado pelas sete espécies encontradas, como L. plantarum, L. paracasei, L. curvatus, L. rhamnosus, $L$. fructivorans, L. parabuchneri e L. brevis.
Devido à alta correlação desses resultados, com o obtido pelo sequenciamento do rRNA $16 \mathrm{~S}$, foi possível concluir que o MALDITOF se mostrou como uma metodologia mais ágil, econômica, robusta e confiável, sendo uma alternativa atraente aos métodos para caracterização bacteriana utilizada em pesquisas e indústrias.

Da mesma forma, foram isolados 669 micro-organismos do queijo Parenica produzido na Eslováquia. A análise de MALDI-TOF indicou que as bactérias mais presentes foram Acinetobacter baumannii, Bacillus cereus, Micrococcus luteus e Staphylococcus warneri. Escherichia coli e Enterobacter cloacae foram os representantes de coliformes mais abundantes, seguidos dos gêneros Citrobacter, Hafnia e Klebsiella. Entre as BAL, os gêneros identificados foram Lactobacillus, Lactococcus e Leuconostoc, sendo Lactococcus lactis, Lactobacillus plantarum, L. coryniformis, L. fructivorans as espécies mais predominantes. Kluyveromyces lactis, Candida zeylanoides e Yarrowia lipolytica foram as leveduras mais frequentes (KAČÁNIOVÁ et al., 2018).

Tabela 1 - Identificação de espécies de lactobacilos isolados de produtos de origem animal por PCR e MALDI-TOF e congruência entre os métodos (DUŠKOVÁ et al.,2012)

\begin{tabular}{cccc}
\hline \multirow{2}{*}{ Espécies de Lactobacillus } & \multicolumn{2}{c}{ Identificações } & Congruência (\%) \\
\cline { 2 - 3 } & PCR & MALDI-TOF & 88 \\
\hline L. brevis & 8 & 9 & 88 \\
L. curvatus & 17 & 15 & 100 \\
L. delbrueckii & 5 & 5 & 75 \\
L. fermentum & 4 & 3 & - \\
L. fructivorans & 0 & 2 & 100 \\
L. johnsonii & 11 & 11 & 94 \\
L. paracasei & 18 & 17 & 86 \\
L. plantarum & 7 & 6 & 97 \\
L. rhamnosus & 38 & 37 & 100 \\
L. sakei & 6 & 6 & \\
\hline
\end{tabular}


Em queijos artesanais da Sérvia, Macrococcus caseolyticus foi o microorganismo mais identificado pela análise proteômica de colônias não-estafilocócicas que desenvolveram no ágar Baird-Parker, seguida de Enterococcus faecalis, Corynebacterium aurimucosum, C. glutamicum e Cronobacter sakazakii e Enterococcus faecium. Entre as colônias de BAL não-lactobacilos oriundas do ágar MRS, foram encontrados Leuconostoc mesenteroides, Enterococcus faecalis, Lactococcus lactis, Enterococcus durans, Lactococcus garvieae, Leuconostoc pseudomesenteroides e Pediococcus pentosaceus (LEDINA et al., 2018).

García-Cayuela et al. (2017) identificaram 100 amostras de Lactococcus lactis isolados de queijos elaborados com leite cru de cabra e ovelha. Desses, foi possível caracterizar três amostras como produtoras de bacteriocinas como lacticina 481, lacticina 3147 e nisina. Com isso, determinou-se que o MALDI-TOF poderia ser usado como uma técnica rápida e confiável para rastrear um grande número de Lactococcus capazes de produzir os lantibióticos.

Mahajan et al. (2017) isolaram 220 amostras de BAL provenientes de produtos lácteos indianos como leite, coalhada e queijo. A análise por MALDI-TOF indicou que as BAL pertenciam a 17 diferentes espécies pertencentes aos gêneros Lactobacillus, Enterococcus, Lactococcus, Leuconostoc e Streptococcus, sendo o resultado confirmado pelo sequenciamento do gene rRNA 16S.

Ao analisarem grãos de kefir brasileiro, Viana et al. (2019) encontraram uma população microbiana composta, em ordem decrescente de concentração, por L. paracasei, Saccharomyces cerevisiae, L. plantarum, Acetobacter pasteurianus e A. syzygii. De acordo com os autores, a aplicação de tal metodologia se mostrou rápida e precisa, podendo ser uma ferramenta importante para o controle microbiológico de culturas iniciadoras.
MALDI-TOF também pode se apresentar como uma alternativa viável para a identificação de micro-organismos isolados no leite, potencialmente causadores de mastite, como Staphylococcus spp., Streptococcus spp., bactérias do grupo coliforme, Enterococcus spp., Trueperella pyogenes, Bacillus spp., Corynebacterium spp., Pasteurella multocida, Proteus spp., Pseudomonas spp., Serratia spp. e Candida spp. (SVENNESEN et al., 2018; NONNEMANN et al., 2019). Nesse sentido, espécimes de patógenos envolvidos em casos de mastite também puderam ser identificados por essa metodologia em amostras de leite bovino, como Staphylococcus aureus $(\mathrm{n}=119)$, Corynebacterium bovis $(\mathrm{n}=48)$, Staphylococcus coagulase-positivo $(\mathrm{n}=37)$, Streptococcus agalactiae $(\mathrm{n}=33)$, Streptococcus uberis $(\mathrm{n}=26)$ e Streptococcus dysgalactiae $(\mathrm{n}=$ 1) (BRAGA et al., 2018). Da mesma forma, Santos et al. (2019) identificaram, por meio de MALDI-TOF, patógenos potencialmente causadores de mastite em amostras de leite caprino, como Staphylococcus simulans $(\mathrm{n}=11)$, Staphylococcus aureus $(\mathrm{n}=4)$, Staphylococcus chromogenes $(\mathrm{n}=3)$, Bacillus spp. $(\mathrm{n}=3)$, Staphylococcus epidermidis $(\mathrm{n}=2)$, Staphylococcus caprae $(\mathrm{n}=1) \mathrm{e}$ Staphylococcus warneri $(\mathrm{n}=1)$. Associado a isso, os autores também observaram que, estatisticamente, existia uma relação diretamente proporcional entre a contagem de células somáticas (CCS) e a presença de tais micro-organismos nas amostras.

MALDI-TOF também se mostrou eficiente na identificação de micro-organismos relacionados à DTA que podem ser veiculadas por leite e derivados. Amostras de $S$. aureus foram identificadas de produtos lácteos produzidos na Itália, como leite, queijo, manteiga e soro. Baseado no espectro formado pela avaliação das 36 amostras de $S$. aureus analisadas, foi possível formar um dendrograma e agrupá-las em oito grupos baseadas na similaridade entre os 
picos obtidos (BÖHME et al., 2012b). Ao pesquisar a presença de patógenos em cinco amostras de queijo muçarela, Böhme et al. (2016) identificaram Staphylococcus aureus, Candida albicans e Debaryomyces hansenii por MALDI-TOF. Da mesma forma, na literatura científica é destacada a possibilidade de identificação, por espectrometria de massa MALDI-TOF, de Listeria monocytogenes em produtos de origem animal como leite, queijos e carne (JADHAV et al., 2014). Nesse sentido, Artursson et al. (2018) ao analisarem amostras de leite cru provenientes de 41 fazendas produtoras de leite bovino e 11 fazendas produtoras de leite caprino, identificaram $L$. monocytogenes em, respectivamente, quatro e uma amostras. Amostras de leite cru também foram submetidas a análise de MALDI-TOF no estudo de Demirci et al. (2019). Os autores identificaram a presença de Salmonella spp. em $2,16 \%$ e Shigella spp. em $0,87 \%$ do total de 231 amostras analisadas.

\section{CONSIDERAÇÕES FINAIS}

A espectrometria de massa MALDI-TOF tem se apresentado como uma metodologia muito promissora quanto sua aplicação na área da microbiologia. A identificação de amostras microbianas por tal método, além de ser rápida e prática, também mostrou resultados equiparáveis aos obtidos na avaliação por métodos moleculares que são considerados "padrão ouro" no quesito, como o sequenciamento do gene rRNA 16S.

Quanto à utilização do MALDITOF na avaliação microbiológica de leite e derivados, embora os resultados obtidos também demonstrem que a prática seja muito promissora, existe um número muito limitado de estudos nesse sentido. Dessa forma, é justificável e necessária a exploração de estudos nessa área para a maior difusão da técnica e construção de banco de dados específicos.

\section{REFERÊNCIAS}

ALATOOM, A. A. et al. Comparison of direct colony method versus extraction method for identification of Gram-positive cocci by use of Bruker Biotyper matrix-assisted laser desorption ionization-time of flight mass spectrometry. Journal of Clinical Microbiology, v. 49, n. 8, p. 2868-2873, 2011.

ANGELAKIS, E. et al. Rapid and accurate bacterial identification in probiotics and yoghurts by MALDI-TOF mass spectrometry. Journal of Food Science, v. 76, n. 8, p. M568-M572 2011.

ANGELETTI, S. Matrix assisted laser desorption time of flight mass spectrometry (MALDI-TOF MS) in clinical microbiology. Journal of Microbiological Methods, v. 138, p. 20-29, 2017.

ANHALT, J. P.; FENSELAU, C. Identification of bacteria using mass spectrometry. Analytical Chemistry, v. 47, n. 2, p. 219225, 1975.

ARTURSSON, K. et al. Foodborne pathogens in unpasteurized milk in Sweden. International Journal of Food Microbiology, v. 284, p. 120-127, 2018.

\section{BARREIRO, J. R. Identificação de patógenos causadores de mastite subclínica por espectrometria de massas, 2010. 75 p. Dissertação (Mestrado em Nutrição e Produção Animal) - Faculdade de Medicina Veterinária e Zootecnia, Universidade de São Paulo, Pirassununga, 2010.}

BÖHME, K. et al. Characterization of Staphylococcus aureus strains isolated from Italian dairy products by MALDI-TOF mass fingerprinting. Electrophoresis, v. 33, n. 15, p. $2355-2364,2012 b$. 
BÖHME, K. et al. Detection of foodborne pathogens using MALDI-TOF mass spectrometry. In: BARROS-VELÁZQUEZ J. Antimicrobial Food Packaging. Amsterdam: Academic Press, 2016. p. 203-214.

BÖHME, K. et al. Spectra Bank: An open access tool for rapid microbial identification by MALDI-TOF MS fingerprinting. Electrophoresis, v. 33, n. 14, p. 2138-2142, 2012a.

BOOR, K. J. et al. A 100-Year Review: Microbiology and safety of milk handling. Journal of Dairy Science, v. 100, n. 12, p. 9933-9951, 2017.

BOTTARI, B. et al. Effective identification of Lactobacillus casei group species: genomebased selection of the gene mutL as the target of a novel multiplex PCR assay. Microbiology, v. 163, n. 7, p. 950-960, 2017.

BRAGA, P. A. C. et al. Rapid identification of bovine mastitis pathogens by MALDI-TOF Mass Spectrometry. Pesquisa Veterinária Brasileira, v. 38, n. 4, p. 586-594, 2018.

CANTÚ, M. D. et al. Sequenciamento de peptídeos usando espectrometria de massas: um guia prático. Química Nova, v. 31, n. 3, p. $669-675,2008$.

DEMIRCI, M. et al. Salmonella spp. and Shigella spp. detection via multiplex real-time PCR and discrimination via MALDI-TOF MS in different animal raw milk samples. Nigerian Journal of Clinical Practice, v. 22, n. 8, p. 1083-1090, 2019.

DUŠKOVÁ, M. et al. Identification of lactobacilli isolated from food by genotypic methods and MALDI-TOF MS. International Journal of Food Microbiology, v. 159, n. 2, p. 107-114, 2012.
FAO. FOOD AND AGRICULTURE ORGANIZATION OF THE UNITED NATIONS. Dairy Production and Products Milk Production. 2019. Disponível em: http:// www.fao.org/dairy-production-products/ production/en/. Acesso em: 15 maio 2019.

FAO/WHO. FOOD AND AGRICULTURAL ORGANIZATION/WORLD HEALTH ORGANIZATION. Guidelines for the evaluation of probiotics in food. London: FAO/WHO, 2002. 11p.

GARCÍA-CAYUELA, T. et al. Rapid detection of Lactococcus lactis isolates producing the lantibiotics nisin, lacticin 481 and lacticin 3147 using MALDI-TOF MS. Journal of Microbiological Methods, v. 139, p. 138-142, 2017.

GAROFALO, C. et al. Bacteria and yeast microbiota in milk kefir grains from different Italian regions. Food Microbiology, v. 49, p. 123-133, 2015.

HAMET, M. F. et al. Selection of EPSproducing Lactobacillus strains isolated from kefir grains and rheological characterization of the fermented milks. LWT - Food Science and Technology, v. 63, n. 1, p. 129-135, 2015.

HOLLAND, R. D. et al. Rapid identification of intact whole bacteria based on spectral patterns using matrix-assisted laser desorption/ionization with time-of-flight mass spectrometry. Rapid Communications in Mass Spectrometry, v. 10, n. 10, p. 1227-1232, 1996.

HORNEFFER, V. et al. Localization of analyte molecules in MALDI preparations by confocal laser scanning microscopy. Analytical Chemistry, v. 73, n. 5, p. 1016-1022, 2001.

IBGE. Instituto Brasileiro de Geografia e Estatística. Pesquisa Trimestral do Leite. 
2019. Disponível em: https://www.ibge. gov.br/estatisticas-novoportal/economicas/ agricultura-e-pecuaria/9209-pesquisatrimestral-do-leite. Acesso em: 15 maio 2019.

INCZEDY, J et al. Compendium of analytical nomenclature. Hoboken: Blackwell Science, 1998. 964 p.

JADHAV, S. et al. Detection of Listeria monocytogenes from selective enrichment broth using MALDI-TOF Mass Spectrometry. Journal of Proteomics, v. 97, p. 100-106, 2014.

KAČÁNIOVÁ, M. et al. Identification of the Slovak traditional cheese "Parenica" microflora. Acta Agraria Debreceniensis, v. 150, p. 227-239, 2018.

KEYS, C. J. et al. Compilation of a MALDITOF mass spectral database for the rapid screening and characterisation of bacteria implicated in human infectious diseases. Infection, Genetics and Evolution, v. 4, n. 3, p. 221-242, 2004.

LASCH, P. et al. Insufficient discriminatory power of MALDI-TOF mass spectrometry for typing of Enterococcus faecium and Staphylococcus aureus isolates. Journal of Microbiological Methods, v. 100, p. 58-69, 2014.

LEDINA, T. et al. MALDI-TOF mass spectrometry for the identification of Serbian artisanal cheeses microbiota. Journal of Consumer Protection and Food Safety, v. 13, n. 3, p. 309-314, 2018.

MAHAJAN, B. et al. MALDI-TOF MS spectrophotometric and $16 \mathrm{~S}$ rRNA gene sequencing identification of probiotic lactic acid bacteria isolated from dairy food products. International Journal of Probiotics and Prebiotics, v. 12, n. 4, p. 199-210, 2017.
MARANGONI, F. et al. Cow's milk consumption and health: A health professional's guide. Journal of the American College of Nutrition, v. 38 n. 3, p. 197-208, 2019.

MARÍN, M. et al. Accurate differentiation of Streptococcus pneumoniae from other species within the Streptococcus mitis group by peak analysis using MALDI-TOF MS. Frontiers in Microbiology, v. 8, p. 698, 2017.

MURRAY, P. R. What is new in clinical microbiology-microbial identification by MALDI-TOF mass spectrometry: a paper from the 2011 William Beaumont Hospital Symposium on molecular pathology. Journal of Molecular Diagnostics, v. 14, n. 5, p. 419-423, 2012.

NACEF, M. et al. MALDI-TOF mass spectrometry for the identification of lactic acid bacteria isolated from a French cheese: The Maroilles. International Journal of Food Microbiology, v. 247, p. 2-8, 2017.

NONNEMANN, B. et al. Bovine mastitis bacteria resolved by MALDI-TOF mass spectrometry. Journal of Dairy Science, v. 102 , n. 3 , p. $2515-2524,2019$.

PAAUW, A. et al. Rapid and reliable discrimination between Shigella species and Escherichia coli using MALDI-TOF mass spectrometry. International Journal of Medical Microbiology, v. 305, n. 4-5, p. 446452, 2015.

PAIVA, D. L. et al. Introdução à Espectroscopia. São Paulo: Cengage Learning, 2010. 716p.

PAUKER, V. I. et al. Improved discrimination of Bacillus anthracis from closely related species in the Bacillus cereus sensu lato group based on MALDI-TOF mass spectrometry. Journal of Clinical Microbiology, v. 56, n. 5, p. e01900-17, 2018. 
POSTERARO, B. et al. MALDI-TOF mass spectrometry in the clinical mycology laboratory: Identification of fungi and beyond. Expert Review of Proteomics, v. 10, n 2, p. 151-164, 2013.

QUIGLEY, L. et al. The complex microbiota of raw milk. FEMS Microbiology Reviews, v. 37, n. 5, p. 664-698, 2013.

SAFFERT, R. T. et al. Comparison of Bruker Biotyper matrix-assisted laser desorption ionization-time of flight mass spectrometer to BD Phoenix automated microbiology system for identification of gram-negative bacilli. Journal of Clinical Microbiology, v. 49, n. 3, p. 887-892, 2011.

SANTOS, K. et al. Identification of mastitis pathogens using MALDI-ToF and its association with somatic cell count in dairy goats. Journal of Dairy Science, v. 102, n. 1, p. 125, 2019.

SEUYLEMEZIAN, A. et al. Development of a custom MALDI-TOF MS database for specieslevel identification of bacterial isolates collected from spacecraft and associated surfaces. Frontiers in Microbiology, v. 9, p. 780,2018 .

SINGHAL, N. et al. MALDI-TOF mass spectrometry: an emerging technology for microbial identification and diagnosis. Frontiers in Microbiology, v. 6, p. 791, 2015.

STEVENSON, L. G. et al. Rapid identification of bacteria in positive blood culture broths by matrix-assisted laser desorption ionizationtime of flight mass spectrometry. Journal of Clinical Microbiology, v. 48, n. 2, p. 444447, 2010.
SVENNESEN, L. et al. Staphylococcus aureus and Streptococcus agalactiae in milk and teat skin from cows in automatic milking systems. In: NATIONAL MASTITIS COUNCIL ANNUAL MEETING, 57, 2018, Tucson. Poster session [...]. Tucson: National Mastitis Council, 2018.

TANAKA, K. et al. Protein and polymer analyses up to $\mathrm{m} / \mathrm{z} 100000$ by laser ionization time-of-flight mass spectrometry. Rapid Communications in Mass Spectrometry, v. 2 , n. 8 , p. 151-153, 1988 .

USDA - United States Department of Agriculture. Brazil: Dairy and Products Annual. 2019. Disponível em: https://www. fas.usda.gov/data/brazil-dairy-and-productsannual-4. Acesso em: 14 maio 2019.

VELOO, A. C. M. et al. The optimization and validation of the Biotyper MALDI-TOF MS database for the identification of Gram-positive anaerobic cocci. Clinical Microbiology and Infection, v. 22, n. 9, p. 793-798, 2016.

VERRAES, C. et al. A review of the microbiological hazards of dairy products made from raw milk. International Dairy Journal, v. 50, p. 32-44, 2015.

VIANA, R. O. et al. Use of Maldi-Tof MS biosensor in microbial assessment of Brazilian kefir grains. Revista Ceres, v. 66, n. 1, p. 72-76, 2019

WATTAL, C. et al. Matrix-assisted laser desorption ionization time of flight mass spectrometry (MALDI-TOF MS) for rapid identification of micro-organisms in the routine clinical microbiology laboratory. European Journal of Clinical Microbiology \& Infectious Diseases, v. 36, n. 5, p. 807-812, 2017. 